\title{
Proses Fabrikasi dan Sifat Mekanik Komposit Polimer dengan Metode Bladder Compression Moulding
}

\author{
G. Nugroho',* dan M. S. R. R. Wantogia ${ }^{1}$ \\ 1Departemen Teknik Mesin dan Industri Fakultas Teknik Universitas Gadjah Mada \\ Yogyakarta 55281, Indonesia \\ Telp. (0274) 521673 \\ *e-mail: gesangnugroho@ugm.ac.id
}

\begin{abstract}
Composite materials have high potential for use in many technical applications. Composite materials have diverse mechanical properties and are easily set according to design requirements. The mechanical properties of polymer composite materials are obtained from various choices of fibers and matrices used to the manufacturing methods. In this study, the tensile strength of carbon fiber is sought with an epoxy resin matrix made by using the bladder compression molding method as well as the manufacturing process of composite formation as a whole. The results obtained, compared to composite materials with the same constituent material but made by the method of vacuum bagging and hand lay-up. The formation of carbon fiber composites by the bladder compression molding (BCM) method produces a higher tensile strength compared to the formation of carbon fiber composites by the vacuum bagging method, in the case formation process by the BCM method is able to increase the tensile strength by $17.48 \%$ from the vacuum bagging method with strength of the pull is $515 \mathrm{MPa}$.
\end{abstract}

Keywords: polymer composites, bladder compression molding, mechanical properties, tensile testing, vacuum bagging.

\begin{abstract}
Abstrak
Material komposit memiliki potensi yang tinggi pada kegunaanya di banyak aplikasi teknik. Material komposit memiliki sifat mekanis yang beragam dan mudah diatur sesuai dengan kebutuhan perancangan. Sifat mekanis material komposit polimer didapatkan dari berbagai pemilihan serat dan matriks yang digunakan hingga metode manufaktur yang digunakan. Pada penelitian ini, dicari kekuatan tarik serat karbon dengan matriks resin epoxy yang dibuat dengan metode bladder compression molding beserta proses manufaktur pembentukan komposit secara keseluruhan. Hasilnya yang diperoleh, dibandingkan dengan material komposit dengan material penyusun yang sama namun dibuat dengan metode vacuum bagging dan hand lay-up. Pembentukan komposit serat karbon dengan metode bladder compression moulding (BCM) menghasilkan kekuatan tarik yang lebih tinggi dibanding dengan pembentukan komposit serat karbon dengan metode vacuum bagging, dimana proses pembentukan dengan metode BCM mampu meningkatkan kekuatan tarik sebesar $17,48 \%$ dari metode vacuum bagging yang kekuatan tariknya sebesar 515 $\mathrm{MPa}$.
\end{abstract}

Kata kunci: komposit polimer, bladder compression moulding, sifat mekanis, uji tarik, vacuum bagging. 


\section{PENDAHULUAN}

Perkembangan teknologi dalam kehidupan manusia dapat memunculkan penemuanpenemuan baru. Dunia teknik material adalah salah satu dari segala bidang keteknikan yang menunjukkan perkembangan yang pesat. Hal ini dikarenakan dalam setiap perancangan keteknikan pemilihan material yang tepat sangat berpengaruh pada rancangan yang diimplementasikan. Banyak variabel dalam teknik material yang dapat dimodifikasi menyesuaikan dengan dana dan kebutuhan rancangan tersebut untuk menciptakan suatu rancangan yang optimal dan efisien.

Pada perkembangannya, para perekayasa material komposit memfokuskan penelitiannya untuk menciptakan material yang lebih kuat, lebih tangguh dan yang lebih ringan untuk mendukung perkembangan teknologi dan konsep perancangan bentuk-bentuk struktur kompleks seperti pada pesawat terbang, struktur otomotif, dan struktur bilah turbin angin (Gururaja and Rao, 2012).

Material komposit adalah bahan struktural yang terdiri dari dua atau lebih bahan yang digabungkan pada tingkat makroskopik dan tidak larut satu sama lain (Gururaja and Rao, 2013). Komposit dengan matriks polimer atau komposit polimer merupakan material yang menggunakan polimer

sebagai matriks dan serat sebagai penguat. Serat yang umum digunakan dalam material komposit polimer adalah serat gelas, serat karbon dan serat organik lainnya (Mardiyati, 2018).

Selain pemilihan serat dan matriks yang digunakan, metode pembentukan material komposit menjadi salah satu faktor yang mempengaruhi sifat mekanis material komposit tersebut (Jagannatha and Harish, 2015). Efektifitas material penguat pada dasarnya bergantung pada daya adhesi serat dan matriks yang digunakan, sehingga faktor kunci dari sifat mekanis material komposit sangat bergantung pada variabel ini (Yosoyima dkk., 1990).

Metode paling sederhana dalam manufaktur material komposit adalah dengan menggunakan metode hand lay-up, dalam metode ini serat penguat yang digunakan dilumuri dengan matriks yang masih cair kemudian diratakan secara manual. Metode ini tidak memerlukan investasi yang besar dalam prosesnya namun memiliki banyak kekurangan dibandingkan dengan metode yang lain (Zhang dkk., 2012).

Pengembangan selanjutnya dari metode hand lay-up adalah metode vacuum bagging. Metode ini lebih baik karena pada proses curing terdapat gaya yang menekan serat dan matriks akibat evakuasi udara di dalam vacumm bag, sehingga matriks dapat terdistribusi dengan baik untuk mencegah terjadinya porositas (Hou and Jensen, 2004). Walaupun demikian, porositas masih banyak ditemukan dalam manufaktur komposit metode ini karena udara yang terjebak antar permukaan serat pre impregnation selama proses lay-up. Besar dan distribusinya dipengaruhi oleh antara lain waktu tahan vakum, pendinginan dan waktu keluar, serta modifikasi material dan proses yang mempengaruhi evakuasi (Hamill dkk., 2015).

Metode lain untuk memaksimalkan hasil manufaktur material komposit adalah dengan metode infusion. Metode ini juga disebut VARIM (Vacuum Assisted Resin Infusion Moulding). Pada metode ini serat yang masih kering diletakkan didalam vacuum bag yang semula dibuat vacuum. Dengan memanfaatkan ruang vakum di dalam vacuum bag resin dialirkan melalui serat kemudian di buang di sebuah wadah bernama resin trap (Goren and Atas, 2008). Dengan menggunakan metode ini distribusi resin akan lebih efisien dan kelebihan resin tidak akan mengganggu struktur komposit yang akan dihasilkan sehingga fraksi volume serat yang diinginkan dapat tercapai (Sevkata and Brahimib, 2011). 
Dalam proses pembuatan komposit, fraksi volume serat hendaknya dimaksimalkan agar dicapai struktur material yang lebih baik. Upaya ini dilakukan dengan memberikan tekanan yang optimal pada material komposit selama proses curing (Guiraud et al, 2012).

Metode bladder compression molding mampu memberikan tekanan yang optimal menggantikan metode autoclave untuk menekan biaya produksi, selain itu penambahan bladder bertekanan membantu menghilangkan kelebihan resin pada proses curing menghasilkan kandungan serat yang lebih tinggi (Anderson and Altan, 2012) dan untuk menjaga keseragaman tebal lapisan penguat dan mempermudah produksi komponen berongga yang kompleks (Hammami and Al-Zarouni, 2001)

Untuk meningkatkan kualitas material komposit yang dihasilkan bladder compression mould dapat dipadukan dengan beberapa metode seperti metode bladder assisted composite manufacturing yang dikembangkan oleh Anderson dan Altan (2014). Teknik ini memanfaatkan bladder yang dipanaskan secara internal yang mampu mengurangi 50\% energi yang dibutuhkan untuk proses curing (Anderson and Altan, 2014). Selain itu metode vacuum assisted resin transfer mould yang dikembangkan oleh Anderson menggunakan bladder fleksibel bertekanan untuk menerapkan tekanan konsolidasi di samping tekanan ambien bentuk awal, segera setelah impregmentasi, dalam penelitiannya mampu meningkatkan volume serat dari $42 \%$ menjadi 53\% (Anderson dkk., 2013).

Tujuan penelitian ini adalah untuk membandingkan sifat mekanis material komposit yaitu kekuatan tarik yang dibuat dengan metode hand lay-up, vacuum bagging, dan bladder compression moulding untuk mendapatkan metode paling optimal agar diperoleh komposit dengan kekuatan mekanis yang baik namun ringan.

\section{METODE PENELITIAN}

Proses penelitian ini diawali dengan pemilihan material serat karbon dan matriks yang digunakan, kemudian dilanjutkan dengan proses pembuatan bladder, proses pembuatan produk spesimen, pengujian tarik untuk masing-masing spesimen dengan metode yang berbeda dan membandingkan hasil uji tarik.

\section{Pemilihan Material}

Material komposit dalam pengujian ini dibentuk dari serat karbon sebagai serat penguat dan resin epoksi sebagai matriksnya. Serat karbon yang digunakan adalah plain weave $1 \mathrm{k} 120 \mathrm{~g}$ yang ditunjukkan pada Gambar 1 dan resin epoksi yang digunakan adalah eposchon A dengan hardener EPH 555 yang ditunjukkan pada Gambar 2.

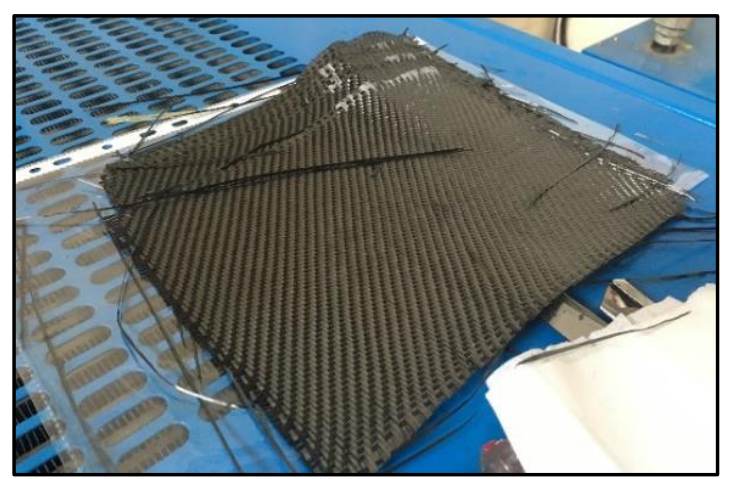

Gambar 1. Serat karbon plain weave $1 \mathrm{k}$ 


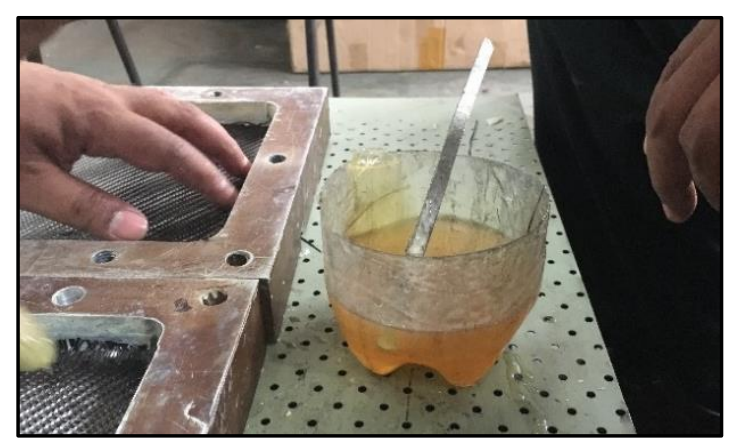

Gambar 2. Campuran eposchon A dan hardener EPH 555

\section{Proses Pembuatan Bladder}

Pembuatan bladder dilakukan dengan menggunakan silikon yang disebut RoomTemperature-Vulcanizing (RTV) Sillicone. Pembuatan bladder dilakukan dengan melapisi cetakan atas maupun bawah dengan komponen RTV silicone rubber A dan B yang sudah siap di curing. Cetakan kemudian ditutup kemudian diberi tekanan. Skema pembuatan bladder ini ditunjukkan pada Gambar 3.

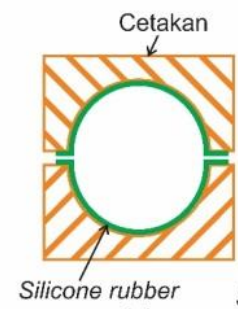

(a)

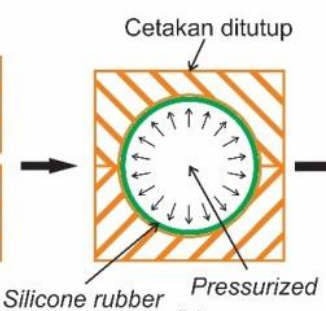

(b)

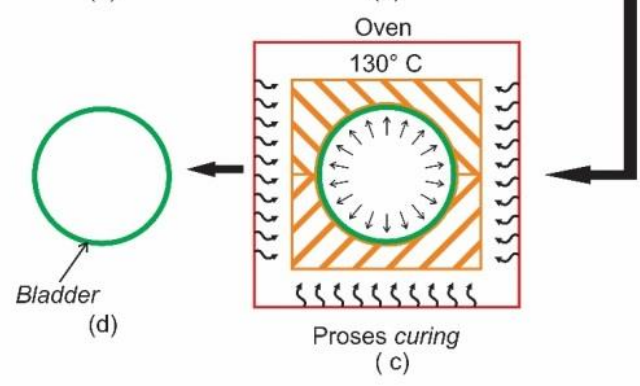

Gambar 3. Skema pembuatan bladder

Dalam penelitian ini spesimen dibuat dengan bentuk plat karena pengujiannya mengikuti standar ASTM D638-02a sehingga cetakan dibuat berbentuk kotak yang memiliki ruang di dalamnya. Bladder kemudian dilepaskan dari cetakan setelah proses curing selesai. Gambar 4 menujukkan cetakan dan bladder yang sudah jadi. 


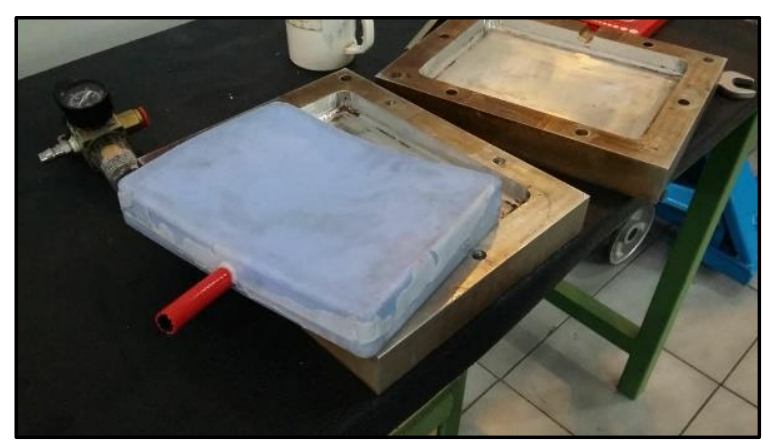

Gambar 4. Hasil bladder yang siap pakai

\section{Pembuatan dan Pengujian Spesimen}

Pembuatan spesimen di dalam penelitian ini akan dibuat 3 variasi metode, dimana metode yang pertama adalah spesimen dibuat dengan metode hand lay-up, metode yang kedua dibuat dengan metode vacuum bagging, dan metode ketiga meggunakan metode bladder compression moulding dengan tekanan 7 bar. Skema pembetukan produk spesimen uji ditunjukkan pada Gambar 5 .

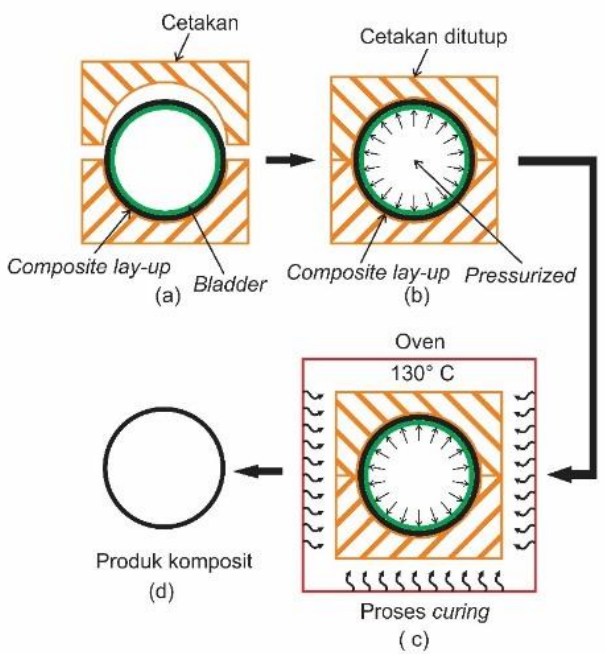

Gambar 5. Skema sederhana pembentukan komposit metode bladder compression moulding

Setiap metode memiliki kekurangan dan kelebihannya masing-masing, namun dalam penelitian ini dicari metode yang memiliki sifat mekanis material komposit terbaik. Serat karbon penguat dibuat 4 lapis karena pengujian dapat dilakukan dengan batas ketebalan spesimen minimal $1 \mathrm{~mm}$. Tabel 1 menunjukkan desain eksperimen selengkapnya.

Tabel 1. Metode manufaktur eksperimen

\begin{tabular}{|c|c|c|}
\hline Spesimen & Metode & Tekanan \\
\hline 1 & Hand Lay-up & - \\
\hline 2 & Vacuum Bagging & Vacuum \\
\hline 3 & Bladder Compression & 7 bar \\
\hline
\end{tabular}


Langkah selanjutnya adalah membuat produk spesimen, dengan mula-mula membersihkan cetakan dari sisa-sisa produksi bladder, kemudian melapisi permukaan cetakan dengan Meguiar's Mirror Glaze sebagai release agent agar komponen spesimen mudah dilepas setelah proses curing selesai. Proses ini dilanjutkan dengan melapisi setiap lapisan serat karbon dengan resin yang sudah dicampur dan ditumpuk hingga 4 lapisan seperti yang ditunjukkan pada gambar 7 dibawah ini.

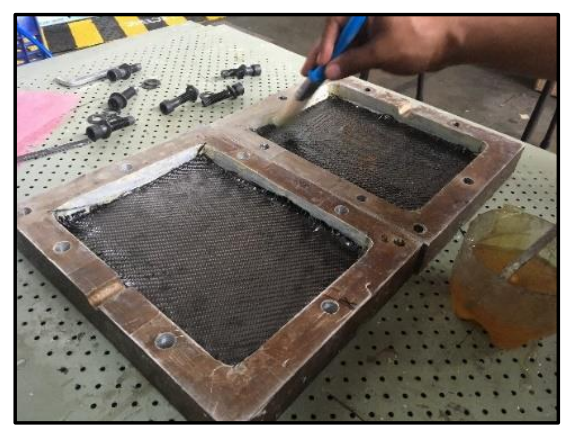

Gambar 6. Melapisi serat karbon dengan resin secara merata

Serat karbon yang sudah dilumuri resin ditumpuk dan diatasnya diberikan release film yang berfungsi untuk memudahkan proses pelepasan produk komposit setelah proses curing dan membuang kelebihan resin untuk mendapatkan volume fraksi serat yang optimal. Kemudian diatas release film dilapisi breather yang berfungsi untuk menahan kelebihan resin agar tidak mengenai bladder sehingga bladder dapat digunakan berulang kali. Gambar 8 menunjukkan komposisi lapisan breather dan pada metode bladder compression moulding.

Langkah terakhir adalah meletakkan bladder dan menutup cetakan untuk kemudian diberikan tekanan sesuai desain eksperimen selama proses curing berlangsung. Gambar 9 dan gambar 10 menunjukkan proses peletakan dan pemberian tekanan pada bladder.

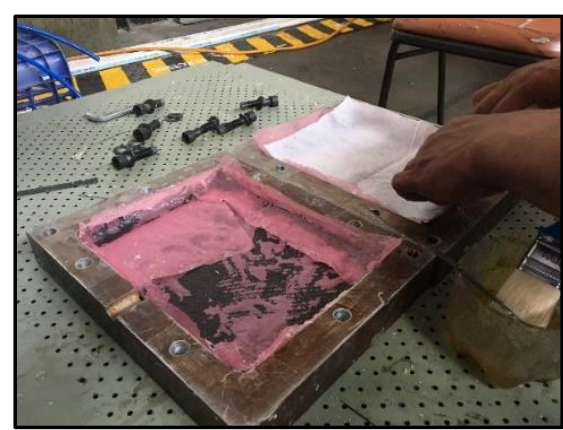

Gambar 7. Komposisi release film dan breather diatas lapisan serat 


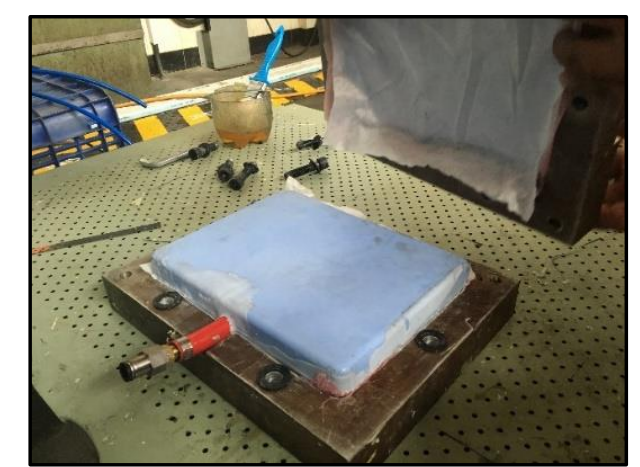

Gambar 8. Peletakkan bladder diatas semua lapisan

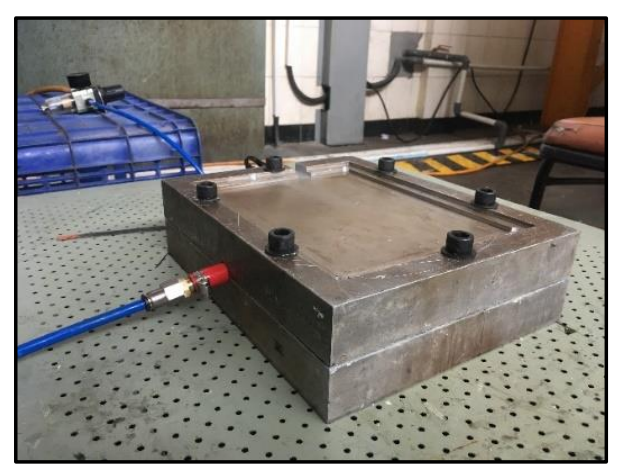

Gambar 9. Pemberian tekanan pada bladder

Setelah proses curing selesai selanjutnya cetakan dibuka, bladder diambil, lapisan breather dan release film dilepas, kemudian laminasi/produk komposit dipotong mengikuti bentuk spesimen sesuai standar ASTM sepeti yang ditunjukkan pada Gambar 11.

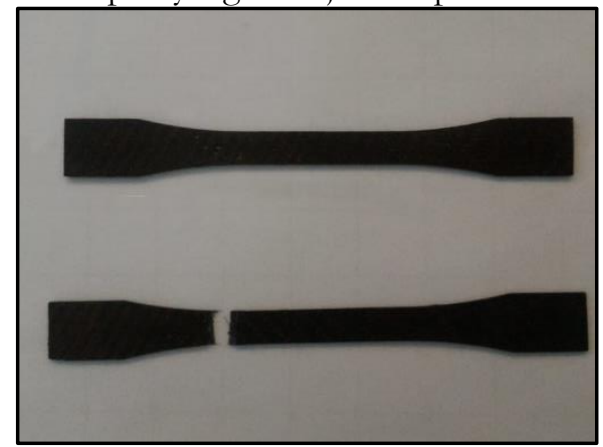

Gambar 10. Spesimen uji tarik sesuai ASTM D638-02a

\section{Uji Kekuatan Mekanis}

Pengujian kekuatan pada penelitian ini adalah pengujian kekuatan tarik, diambil pembebanan tersebut karena aplikasinya pada struktur komposit airframe pesawat. Standar pengujian kekuatan tarik mengacu pada standar ASTM D638-02a. Spesimen diberikan pembebanan hingga $12 \mathrm{kN}$ menggunakan mesin Zwick Z020 pada temperatur ruangan. Beban diberikan pada spesimen hingga spesimen mengalami kegagalan atau patah. Pemanjangan dan 
beban maksimal kemudian dicatat. Pengujian dilakukan lima kali pada setiap metode dan nilai rata-rata hasil pengujian akan menentukan kekuatan tarik pada material komposit.

\section{HASIL DAN PEMBAHASAN}

Pengujian spesimen menghasilkan data, kekuatan tarik untuk masing-masing metode pembentukan komposit. Berikut adalah penjelasan dan hasil pengujian tarik spesimen.

Hasil pengujian tarik diambil dari 5 spesimen dengan berbagai metode eksperimen pembentukan komposit. Yang pertama adalah dengan metode hand lay-up, hasil pengujian tarik metode ini adalah sebesar $329 \mathrm{Mpa}$ (H. Rahmani et al, 2014). Selanjutnya dengan menggunakan metode vacuum bagging. Hasil uji tarik yang didapatkan dengan pembentukan komposit metode ini sebesar $515 \mathrm{MPa}$ (T. D. Jagannatha and G. Harish, 2015). Ada peningkatan sebesar 56,53\% dari metode hand lay-up.

Nilai kekuatan tarik tertinggi diperoleh dari komposit dengan metode manufaktur bladder compression moulding. Tabel 2 dibawah ini menunjukkan data yang diperoleh dari masingmasing spesimen dalam pembentukan komposit metode BCM dan tabel 3 menunjukkan ratarata hasil yang diperoleh pada Tabel 2.

Tabel 2. Kekuatan tarik spesimen BCM

\begin{tabular}{c|c|c|c|c|c|c|c} 
& Force & $\mathrm{E}_{\mathrm{t}}$ & $\mathrm{E}_{\mathrm{Sec}}$ & $\sigma_{\mathrm{M}}$ & $\mathrm{h}$ & $\mathrm{b}$ & $\mathrm{A}_{0}$ \\
No. & $\mathrm{N}$ & $\mathrm{MPa}$ & $\mathrm{MPa}$ & $\mathrm{MPa}$ & $\mathrm{mm}$ & $\mathrm{mm}$ & $\mathrm{mm}^{2}$ \\
\hline 1 & 12091,81 & 58500 & 55400 & 598 & 1,61 & 12,56 & 20,22 \\
\hline 2 & 12399,34 & 58900 & 53500 & 564 & 1,76 & 12,5 & 22,00 \\
\hline 3 & 13879,49 & 55200 & 55000 & 620 & 1,79 & 12,5 & 22,38 \\
\hline 4 & 12780,43 & 61100 & 58900 & 627 & 1,63 & 12,5 & 20,38 \\
\hline 5 & 12932,80 & 52400 & 53700 & 616 & 1,67 & 12,58 & 21,01
\end{tabular}

Tabel 3. Rata-rata kekuatan tarik spesimen BCM

\begin{tabular}{c|c|c|c|c|c|c|r} 
Series & Force & $\mathrm{E}_{\mathrm{t}}$ & $\mathrm{E}_{\mathrm{Sec}}$ & $\sigma_{\mathrm{M}}$ & $\mathrm{h}$ & $\mathrm{b}$ & $\mathrm{A}_{0}$ \\
$\mathrm{n}=5$ & $\mathrm{~N}$ & $\mathrm{MPa}$ & $\mathrm{MPa}$ & $\mathrm{MPa}$ & $\mathrm{mm}$ & $\mathrm{mm}$ & $\mathrm{mm}^{2}$ \\
\hline$\overline{\mathrm{x}}$ & 12816,77 & 57200 & 55300 & 605 & 1,692 & 12,53 & 21,20 \\
\hline $\mathrm{s}$ & 678,97 & 3440 & 2170 & 25,5 & 0,0795 & 0,03899 & 0,96 \\
\hline $\mathrm{v}[\%]$ & 5,30 & 6,01 & 3,93 & 4,22 & 4,70 & 0,31 & 4,53
\end{tabular}

Gambar 11 dibawah ini menunjukkan grafik perbedaan kekuatan tarik yang dimiliki masing-masing metode pembentukan komposit polimer.

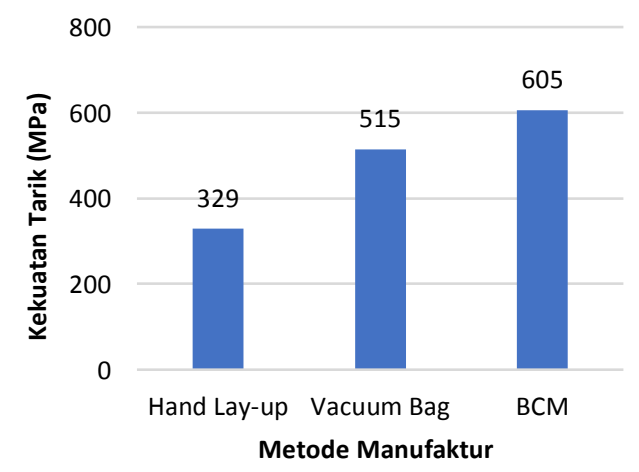

Gambar 11. Grafik kekuatan tarik pada berbagai metode manufaktur komposit 
Dari hasil yang diperoleh didapati pembentukan komposit polimer dengan metode BCM merupakan metode yang paling optimal untuk memperoleh sifat mekanis komposit yang baik. Hal ini sesuai dengan beberapa penelitian yang menjadi referensi pada tulisan ini, dimana secara berurutan sifat mekanis komposit yang dihasilkan adalah dari yang tertinggi hingga terendah yang baik dihasilkan oleh metode berikut Hand lay-up > V acuum Bagging > BCM.

\section{KESIMPULAN}

Kekuatan tarik dalam perbandingan hasil yang didapat pada masing-masing metode adalah sebagai berikut:

- Hand Lay-up = $329 \mathrm{MPa}$

- Vacuum Bagging = $515 \mathrm{MPa}$

- $\mathrm{BCM}=605 \mathrm{MPa}$

Dengan menggunakan metode manufaktur BCM kekuatan tarik spesimen uji mampu meningkat $17,48 \%$ dari metode vacuum bagging.

\section{DAFTAR PUSTAKA}

A. Goren and C. Atas, "Manufacturing of Polymer Matrix Composites using Vacuum Assisted Resin Infusion Molding," International Scientific Journal, World Academy of Materials and Manufacturing Engineering, vol. 34, no. 2 (2008) pp. 117-120.

A. Hammami and A. Al-Zarouni, "Investigation of the RTM / Bladder Molding Process," in International Committee on Composite Materials, Beijing, 2001.

E. Sevkata and M. Brahimib, "The Bearing Strength of Pin Loaded Woven Composites Manufactured by Vacuum Assisted Resin Transfer Molding and Hand Lay-up Techniques," Elsevier, Procedia Engineering, vol. 10 (2011) pp. 153-158.

H. Rahmani, S. H. M. Najafi and A. Ashori, "Mechanical performance of epoxy/carbon," Journal of Reinforced Plastics \& Composites, vol. 33, no. 8 (2014) pp. 733-740.

J. P. Anderson and M. C. Altan, "Bladder Assisted Composite Manufacturing (BACM): Challenges and Opportunities," in Polymer Processing Society Europe-Africa Conference, Tel Aviv, 2014.

J. P. Anderson and M. C. Altan, "Properties of Composite Cylinders Fabricated by Bladder Assisted Composite Manufacturing," ASME, Journal of Engineering Materials and Technology, vol. 134, no. 4, 2012.

J. P. Anderson, A. J. Kelly and M. C. Altan, "Fabrication of Composite Laminates by VacuumAssisted Resin Transfer Molding Augmented with an Inflatable Bladder," in American Society for Composites 28th Technical Conference, Pennsylvania, 2013.

J. Zhang, K. Chaisombat, S. He and C. H. Wang, "Hybrid Composite Laminates Reinforced with Glass/Carbon Woven Fabrics for Light Weight Load Bearing Structures," Elsevier, Material and Design, vol. 36, (2012) pp. 75-80.

L. Hamill, T. Centea and S. Nutt, "Surface Porosity During Vacuum Bag-only Prepreg Processing: Causes and Mitigation Strategies," Elsevier, Composites Part A: Applied Science and Manufacturing, vol. 75 (2015) pp. 1-10.

M. N. Gururaja and A. N. Hari Rao, "A Review on Recent Applications and Future Prospectus of Hybrid Composites," International Journal of Soft Computing and Engineering (IJSCE), vol. 1, no. 6, January 2012, pp. 352-355. 
M. N. Gururaja and A. N. Hari Rao, "Effect of An Angle-ply Orientation on Textile Properties of Kevlar/Glass Hybrid Composites," International Journal on Theoratical and Applied Research in Mechanical Engineering, vol. 2, no. 3 (2013), pp. 63-67.

Mardiyati, "Komposit Polimer sebagai Material Tahan Balistik," Jurnal Inovasi Pertahanan dan Keamanan, vol. 1, no. 1, Februari 2018, pp. 20-28.

O. Guiraud, P. J. Dumont, L. Orgéas and D. Favier, "Rheometry of compression moulded fibre-reinforced polymer composites: Rheology, compressibility, and friction forces with mould surfaces," Elsevier, Composites Part A: Applied Science and Manufacturing, vol. 43, no. 11 (2012) pp. 2107-2119.

R. Yosoyima, K. Morimoto, T. Susuki, A. Nakajima and Y. Ikada, Adhesion and Bonding in Composites, New York: Marcel Dekker Inc., 1990.

T. D. Jagannatha and G. Harish, "Mechanical Properties of Carbon/Glass Fiber Reinforced Epoxy Hybrid Polymer Composites," International Journal of Mechanical Engineering and Robotics Research, vol. 4, no. 2, April 2015.

T. Hou and B. J. Jensen, Evaluation of Double-Vacuum-Bag Process For Composite Fabrication, Virginia: NASA Langley Research Center, 2004. 